\title{
Touch the Plaque Open Technique of LAD Endarterectomy During CABG Surgery Guarantees Fair Postoperative Outcome and Preserved LV Functional Performance
}

\author{
AHMED SABER, M.D., F.R.C.S. (Glasg) \\ The Department of Cardiothoracic Surgery, Faculty of Medicine, Cairo University, Cairo, Egypt
}

\begin{abstract}
Background: The rising number of severely diffused diseased left anterior descending (LAD) coronary artery (which is the most important target) met during coronary artery bypass grafting (CABG) surgeries represents a challenging test to the cardiac surgeon and requires a more complex maneuvers rather than simple distal segment arteriotomy anastmosis in order to secure complete myocardial revascularization which is the main goal of the surgery. Touch the plaque open technique of LAD endarterectomy combined with left internal thoracic (mammary) artery (LIMA) patch plasty is one of the available solutions.
\end{abstract}

Aim of Study: Impact of application of touch the plaque open technique of LAD endarterectomy combined with LIMA patch plasty on the postoperative outcome, left ventricular (LV) function and clinical status of the patients is evaluated.

Patients and Methods: This retrospective observational non-randomized study included 21 patients who presented with ischemic heart disease (IHD) requiring primary surgical myocardial revascularization (primary CABG surgery). Included patients are those with multi-vessel coronary artery disease, left main or left main-equivalent coronary artery disease and one or two coronary artery disease. They had anginal pain grade III according to Canadian Cardiovascular Society (CCS) grading of angina pectoris. Intraoperatively they had long segment-diffusely diseased LAD that was dealt with touch the plaque open technique of LAD endarterectomy combined with LIMA patch plasty. Postoperative mortality, morbidity outcomes, LV function, overall hospital complications, haemodynamic and functional clinical status, and overall one-year survival were evaluated.

Results: Mean age was $58.23 \pm 7.54$ years. Female patients represented $42.85 \%$. The overall hospital complication rate was $28.57 \%$. No mortality happened during the follow-up period (overall one-year survival rate was $100 \%$ ). Preoperative mean LVEF\% was $46.3 \pm 3.7 \%$ (range $37-59 \%$ ). Evident improvement in both clinical status and LVEF\% was observed. Prior-to-hospital discharge LVEF\% showed mild improvement with a mean $50.1 \pm 1.3 \%(p>0.05)$ and at one-year follow-up

\footnotetext{
Correspondence to: Dr. Ahmed Saber, E-Mail: ahmedsaber78@yahoo.com ahmedsaber78@cu.edu.eg
}

showed significant improvement with a mean $57.5 \pm 3.4 \%$ $(p<0.05) .85 .71 \%$ were in CCS grade I at one-year follow-up $(p<0.01)$.

Conclusion: Touch the plaque open technique of LAD endarterectomy combined with LIMA patch plasty provides satisfactory operative and postoperative results without adding more burden to the surgery. It secures complete revascularization of the LAD myocardial territory and improvement of the LV function and resultant improvement of the clinical and haemodynamic status of the patients. Utilization of LIMA patch plasty and strict anticoagulation management postoperatively is highly recommended.

Key Words: Touch the plaque open technique - LAD endarterectomy-CABG.

\section{Introduction}

CORONARY Artery Bypass Grafting (CABG) surgery is the gold standard operation for ischemic heart disease (IHD) patients that aims to ensure better life style and longer living periods. Thus, its main target is to provide complete and total revascularization of the myocardium. The left anterior descending (LAD) artery per se is the most important target of CABG surgery and complete revascularization of its myocardial territory has significant good results as opposed to higher mortality rates in cases of incomplete revascularization [1]. Unfortunately, because of the rising number of cases done percutaneousely using complex maneuvers but still not ensuring complete myocardial revascularization, the cardiac surgery operation theater now faces many complicated and challenging CABG surgeries that require more complex interventions of the coronary targets [2].

Atherosclerosis affecting coronary arteries can be diffuse in longitudinal or consecutive fashion causing partial or total (complete) obstruction of the vessel. Multiple aetiological agents contribute to it like diabetes mellitus, dyslipidemia, connective 
tissue diseases, multiple stents in coronaries and chronic renal disease [3]. Its distribution, extension and severity risingly increase with time. However, it is difficult to predict its rate of progression making a decision of unsuitability of a single patient for CABG uncommon [3]. Diffusely diseased LAD represents a challenging surgical entity that may require more than simple arteriotomy anastmosis. Myocardial ischemia in its territory may be potentially only treated by a more aggressive surgical maneuver. Anastmosis to its distal segment may be useless and non-beneficial [4] .

The surgical technique of coronary endarterectomy was first introduced by Bailey et al., in 1957 for dealing with severely diffused atherosclerotic coronary vessels [5]. Since then, the technique has been adapted by many cardiac surgeons as an option to obtain complete revascularization of the diffusely diseased LAD [6]. Many recent reports and publications address favorable long term outcomes of coronary endarterectomy and state that it is a safe optional procedure [7].

It is controversial to adapt an optimal technique of coronary endarterectomy. However, many methods are presented. Of these, touch the plaque technique (closed-traction and open) are generally used [3].

This work examines and evaluates the beneficial value of the "touch the plaque open technique" of LAD endarterectomy combined with left internal thoracic (mammary) artery (LIMA) patch plasty on the postoperative outcome parameters and preservation of left ventricular (LV) function.

\section{Patients and Methods}

\section{Study design:}

This retrospective observational non-randomized study included 21 patients who presented with ischemic heart disease (IHD) requiring primary surgical myocardial revascularization (primary CABG surgery) done by a single cardiothoracic surgeon. The study was conducted after obtaining a written informed consent of each and every participant. All the surgeries were carried out in Egypt (conducted in operating theater of the department of Cardiothoracic Surgery, Faculty of Medicine, Cairo University) using standard open heart surgical procedures. The study was conducted in the period between January 2016 and January 2019. The data of the study population was collected from the cardiothoracic section computer database supplemented by a review of hospital records.
All the data were studied and thoroughly evaluated in the preoperative, intraoperative and postoperative periods (for one year).

\section{Inclusion and exclusion criteria:}

The study population included adult patients scheduled for elective primary CABG surgery presenting with multi-vessel coronary artery disease, left main or left main-equivalent coronary artery disease and one or two coronary artery disease. They had anginal pain grade III according to Canadian Cardiovascular Society (CCS) grading of angina pectoris. Intraoperatively they had long segment-diffusely diseased LAD. Excluded patients were those with concomitant valvular heart disease (from any aetiological factor including ischemic mitral valve disease) and patients with associated pathologies requiring surgical intervention such as ascending aortic aneurysm/dissection, left ventricular aneurysm, and ventricular septal defects.

\section{Management regimen:}

\section{Preoperatively:}

The collected preoperative data from the study population were age, sex, risk factors of cardiovascular disease e.g. hypertension, smoking, diabetes, dyslipidemia, post-menopause, and family history of susceptibility to IHD, previous myocardial infarction (MI) and history of CCU admission, history of coronary angioplasty and stenting, left ventricular ejection fraction (LVEF), European System for Cardiac Operative Risk Evaluation (EuroSCORE) II, syntax score and history of chronic renal disease and peripheral vascular disease. Diabetics were subjected to strict (tight) glycemic control measures using different doses of insulin therapy (individualized based on endocrinological consultations) for the preoperative 7-10 days period aiming to keep blood glucose measures 110$150 \mathrm{mg} / \mathrm{dl}$. This included combination of scheduled subcutaneous insulin therapy and repeated insulin injections according to Matias protocol [8]. Acetylsalicylic acid was discontinued 5 days before surgery while clexane and clopidogril were discontinued 12 hours and 5-7 days respectively before it. All patients received sedative premedications (oral valium $5 \mathrm{mg}$ at the night of surgery and intramuscular morphia $10 \mathrm{mg}$ at the morning of surgery).

\section{Intraoperatively:}

All patients were pre-medicated by intravenous midazolam $(0.1 \mathrm{mg} / \mathrm{kg})$ at the operating room, patients were monitored with electrocardiogram, invasive arterial blood pressure using an arterial catheter connected to a pressure transducer, central 
venous catheter inserted in the internal jugular vein, nasopharyngeal temperature probe, pulse oximetry, capnography, urinary catheter and frequent arterial blood gases (ABGs) measurements for $\mathrm{pH}$, electrolytes and glucose every 15 minutes. Diabetic patients were subjected to intra-operative tight (strict) glycemic control using uniform intravenous insulin infusion protocol (prepared by mixing 100 units of insulin with 50ml $0.9 \%$ Normal Saline) aiming to keep blood glucose measures $110-150 \mathrm{mg} / \mathrm{dl}$. General anesthesia was induced. Anticoagulation was established with an initial dose of heparin (300-400IU/kg) to get activated clotting time (ACT) higher than 400s, additional heparin was given on need to maintain ACT higher than 400 s during bypass time. At the end of CPB, heparin was reversed by protamine chloride at a $1: 1$ ratio of the loading dose, regardless of the total heparin dosage. Operative technique was always the same for all the study population. All the patients were operated upon via standard vertical median sternotomy, Cardiopulmonary bypass (CPB) was initiated with aorto-caval cannulation, ascending aorta was cross clamped and cardioplegia was received by warm blood intermittent antegrade technique every 20 minutes. The priming volume was always minimized to $800-1000 \mathrm{~mL}$. Core body temperature during $\mathrm{CPB}$ was $30-32^{\circ} \mathrm{C}$. The pump flow was targeted between 2.0 and $2.8 \mathrm{~L} / \mathrm{min} / \mathrm{m} 2$ and the target mean arterial pressure was settled at $60 \mathrm{mmHg}$. First, the harvested reversed saphenous vein grafts (SVGs) were anastomosed to other target coronaries using $7 / 0$ monofilamentous sutures in a direct continuous fashion. Then, LAD endarterectomy (done by touch the plaque open technique through long LAD arteriotomy starting from a suitable relatively healthy landing zone about 0.5 $\mathrm{cm}$ distal to the diseased segment and extending proximally up to $0.5 \mathrm{~cm}$ of another relatively healthy landing zone with opening the whole diseased segment and total removal of the plaque under direct visualization) and long LIMA patch plasty was done using 7/0 monofilamentous sutures in a direct continuous fashion. Proximal anastmoses were carried out on beating heart after instillation of hot shot dose and unclamping the ascending aorta regaining myocardial activity using partial aortic side occlusion clamping using $6 / 0$ monofilamentous sutures in a direct continuous fashion. The operative variables included intraoperative mortality, aortic cross clamping time, CPB time, number of grafts done, blood glucose level (during and after CPB), metabolic acidosis, haemodynamics, difficulty of weaning-off CPB, inotropic support medications, need for intra-aortic balloon pump (IABP) insertion.

\section{Postoperatively:}

Patients were transferred to the Intensive Care Unit (ICU) for stabilization prior to shifting to regular room receiving anticoagulants and antiplatelets after passing 6 hours extending to 6 months postoperatively controlling INR to be 1.5-2 [3] Patients were followed-up for one year postoperatively by clinical status and echocardiographic evaluation. The postoperative studied variables included ICU parameters (duration of mechanical ventilation, duration of inotropic support, total blood loss, blood glucose level, total duration of ICU stay), operative mortality, total hospital stay, mortality within one-year follow-up, and adverse postoperative complications including myocardial infarction, cerebrovascular accidents, pulmonary embolism, peripheral arterial/venous thromboembolism, low cardiac output syndrome, rhythmic complications, hemorrhagic complications, respiratory complications, acute renal failure, deep and superficial wound infections. The overall hospital complication rate was calculated on the basis of the number of patients with at least one hospital complication.

\section{Definitions of adverse variables:}

Perioperative myocardial infarction was defined as creatinine kinase-MB elevation of 5 or more times the upper limit of normal and the presence of any new Q wave within 48 hours postoperatively or the disappearance of the $\mathrm{R}$ wave on the postoperative electrocardiogram (ECG). Cerebrovascular accident (CVA) was defined as a new stroke or a transient ischemic attack (TIA) for at least 24 hours. Low cardiac output syndrome was defined as the need for the use of two catecholamines above $10 \mathrm{microgram} / \mathrm{kg} / \mathrm{min}$ dose or the use of an intraaortic balloon pump (IABP). Operative mortality was defined as any death occurring during the 30 days postoperatively. Rhythmic complications were defined by the presence of a supraventricular or ventricular rhythm disorder. Hemorrhagic complications were defined by re-operation to control bleeding or to relieve cardiac tamponade. Respiratory complications were defined by the development of pneumonia, pulmonary atelectasis, and respiratory failure (prolonged ventilation more than 48 hours postoperatively, re-intubation or tracheostomy). Acute renal failure was defined as a rise in the creatinine level (absolute $\geq 0.3 \mathrm{mg} / \mathrm{dl}$, percentage $\geq 50 \%$ ) in need for renal replacement therapy or the need for dialysis sessions (excluding patients requiring dialysis before the operation). Preoperative chronic renal failure was defined as a creatinine clearance of less than $30 \mathrm{ml} / \mathrm{min}$. Preoperative peripheral vascular disease was defined 
as the presence of lower limb arterial disease stage I or II according to Leriche and Fontaine classification or a history of vascular surgery. Deep surgical wounds (sternal and lower limbs) infections were defined as a surgical infection occurring within 30 days, extending beyond the deep tissue plane with bacteriological samples of positive infected tissues or purulent discharge.

\section{Statistical analysis:}

All patients' data were tabulated and processed using SPSS V13.0 (SPSS Inc., Chicago, IL) for Windows 2007. Quantitative variables were expressed using mean and standard deviation, and were compared using $t$-student test. Qualitative variables were compared using Chi-square test or Fischer's exact test when appropriate. Correlation between parameters was performed using Spearman's rank correlation coefficient. In all tests, $p$ value was considered significant when $p<0.05$, highly significant when $p<0.01$ and extremely significant when $p<0.001$.

\section{Results}

\section{Preoperative data:}

The study population were $12(57.14 \%)$ men and $9(42.85 \%)$ women whose ages ranged from 45 to 67 years with a mean age $58.23 \pm 7.54$ years. All patients had undergone a thorough clinical evaluation which included proper history taking, general, chest and cardiac examination. All patients were in CCS grade III. Family history of IHD was positive in $7(33.33 \%)$. Smokers represented 10 (47.61\%). Hypertensives were 14 (66.66\%). Dyslipidemia was prevalent in 16 (76.19\%). The other studied variables showed: Previous MI in 10 (47.61\%), history of CCU admission in $9(42.85 \%)$, history of PCI and stenting in 12(57.14\%), mean LVEF\% was $46.3 \pm 3.7 \%$ (range $37-59 \%$ ), mean syntax score was $36 \pm 3$, EuroSCORE II was 1.3 (0.76-1.68), chronic renal disease in $1(4.76 \%)$, peripheral vascular disease in $1(4.76 \%)$, left main or LM equivalent coronary artery disease in 10 $(47.61 \%)$, three or more coronary artery disease in $15(71.42 \%)$, less than three coronary artery disease in $6(28.57 \%)$ and mean creatinine value was $1.02 \pm 0.13 \mathrm{mg} / \mathrm{dl}$. Diabetics were $16(76.19 \%)$. Their mean fasting blood glucose (FBG) level prior to surgery was $159.3 \pm 21.2 \mathrm{mg} / \mathrm{dl}$. No patient received preoperative intra-aortic balloon insertion.

\section{Operative data:}

All patients were submitted for primary CABG using the same technique of LAD endarterectomy (which is done by touch the plaque open technique through long LAD arteriotomy and total removal of the plaque under direct visualization) and long LIMA patch plasty (Figs. 1,2) and reversed SVGs for other coronary artery targets with the help of heart-lung machine and antegrade warm blood intermittent cardioplgia given every 20 minutes. No intraoperative mortality happened as well as no IABP insertion was needed to assist haemodynamics. Metabolic acidosis was encountered and continuously corrected in $5(23.80 \%)$, yet it was controlled before transferring the patients to ICU and no one faced persistant acidosis. All patients transferred to ICU on epinephrine infusion $5 \mathrm{mi}-$ crogram $/ \mathrm{kg} / \mathrm{min}$. as a supportive physiological dose for the initial 24 hours postoperatively and norepinepherine was added to $11(52.38 \%)$ to control diabetic vasculopathy (vasoplegia). Haemodynamic parameters during the operation were recorded. Mean total operative time was $189.18 \pm$ $20.44 \mathrm{~min}$., mean total bypass time was $100.25 \pm$ $10.22 \mathrm{~min}$. and mean total cross clamp time was $61.35 \pm 24.33 \mathrm{~min}$. Three or more coronary artery targets were encountered in $15(71.42 \%)$ and less than three coronary artery targets in $6(28.57 \%)$. Smooth weaning-off bypass was achieved in 18 $(85.71 \%)$. Electrical cardioversion was needed in $3(14.28 \%)$ to achieve weaning.

\section{Postoperative data:}

All the patients were discharged to the ICU mechanically ventilated. Patients were discharged from the ICU when haemodynamically stable on no inotropic support, with no drains and with satisfactory postoperative laboratory results and ECG. The mean period of the total ICU stay was $2.77 \pm 0.3$ days. The mean duration of the total hospital stay was $8.47 \pm 2.3$ days. No mortality happened in the ICU period or during the hospital stay. Atrial Fibrillation (AF) occurred in 3 (14.28\%). No perioperative MI, cerebrovascular accidents, respiratory complications or acute renal failure were faced. The mean total duration of mechanical ventilation was $6.5 \pm 3.7$ hours, mean duration of inotropic support was $13.8 \pm 4.6$ hours and mean total blood loss was $458.17 \pm 358.1 \mathrm{ml}$. Low cardiac output syndrome (due to ventricular arrhythmias) occurred in $1(4.76 \%)$ who needed IABP insertion and experienced successful hemodynamic support. It was un-eventfully and safely discontinued after 36 hours. Haemorrhagic complication was faced with $1(4.76 \%)$ who required urgent re-exploration to control bleeding. Whereas deep surgical wound infection was not present, superficial surgical wound infection was encountered in $5(23.80 \%)$ who responded to frequent dressings. The overall hospital complication rate was $6(28.57 \%)$. After hospital discharge, patients were followed-up for 
one year. Patients were called after a mean period of $352.19 \pm 22.44$ days. The mean period for return to work was $65.21 \pm 9.33$ days. No mortality happened during the follow-up period (overall oneyear survival rate was 100\%). Evident improvement in both clinical status and LVEF\% was observed. Prior-to-hospital discharge LVEF\% showed mild improvement with a mean $50.1 \pm 1.3 \%(p>0.05)$ and at one-year follow-up showed significant improvement with a mean $57.5 \pm 3.4 \%(p<0.05) .18$ $(85.71 \%)$ patients were in CCS grade I at one-year follow-up $(p<0.01)$.

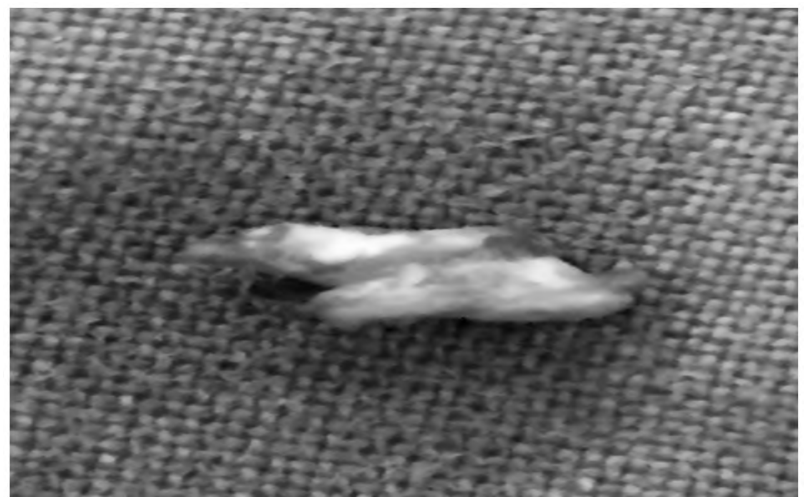

Fig. (1): A specimen of removed plaque.

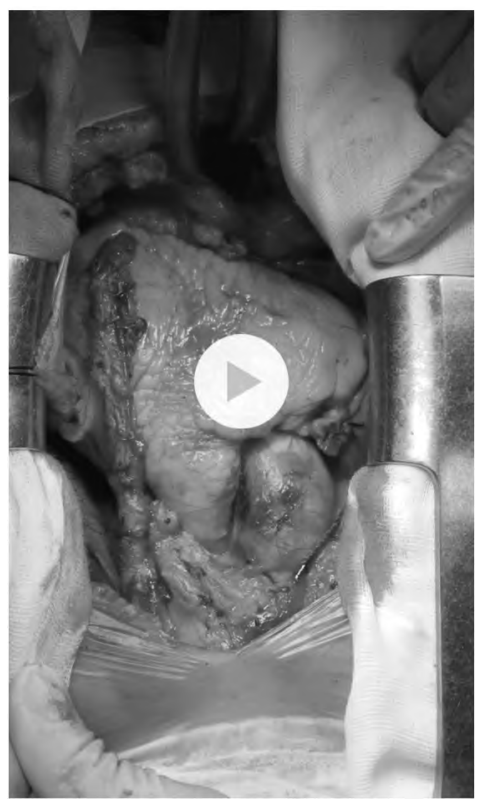

Fig. (2): LAD anastmosis after open endarterectomy and LIMA patch plasty.

\section{Discussion}

It is agreed upon that incomplete myocardial revascularization of the LAD in particular during $\mathrm{CABG}$ operation represents an independant predictor of failed surgery and prompt mortality postoperatively. It is the principal goal of CABG to provide total and complete myocardial revascular- ization of all possible coronary vessel targets especially the LAD [9]. The presence of adequate viable areas of the myocardium favors successful surgical intervention and represents the indication of CABG. Necrotic non-viable large areas of the myocardium make the procedure difficult to find suitable healthy anastmotic sites [3].

Diffuse atherosclerotic coronary lesions causing variable degrees of coronary occlusion stimulate collateral vascular formation that guard against massive ischemia of the myocardium [3]. Moreover, they lead to silent picture of reduced coronary flow reserve and the resultant chronic low-flow ischemia and myocardial remodeling. These would aggravate the condition towards myocardial dysfunction and heart failure [10]. Different therapeutic interventions emerged towards complete myocardial revascularization. Event-free survival shows indifference between CABG and stenting in patients with high coronary flow reserve but $\mathrm{CABG}$ is much more superior and highly effective in those with reduced coronary flow reserve [3].

Diffused LAD rather than affected by focal proximal and/or midsegment lesion represents a real difficult test for surgeons carrying out $\mathrm{CABG}$ surgery enforcing them to apply more complex maneuvers to ensure complete revascularization which might not be applicable by the conventional technique of simple arteriotomy and anastmosis in the distal segment of the LAD which will not provide sufficient blood flow to diagonals and the important septal perforators [11,12]

Many factors decide the optimal surgical method to achieve complete myocardial revascularization including the coronary vessel nature, plaque extension and suitable healthy soft area for grafting. Severely and diffusely diseased vessel without suitable proximal area for anastmosis leads to the need of a more aggressive and complex surgical interventional technique [3]. Thus, diffusely diseased LAD may be best dealt with endarterectomy from the start of CABG [7].

Whereas the conventional standard anastmotic bypass technique by looking for a suitable soft area for grafting is not usually feasible in diffusely diseased LAD, more complex methods are applied. The "No touch the plaque" techniques including jumping multi-bypasses, sequential bypasses and hybrid intervention represent the less invasive ones. The "Touch the plaque" techniques are more suitable for the aggressive severe and diffuse plaques. They include long segment anastmosis, patch plasty and endarterectomy with/without patch 
plasty. Cases with limited length non-focal plaques may benefit from extending the arteriotomy incision through the whole lesion opening it and crosscovered grafting in a long segment anastmosis fashion or patch plasty technique. However, severer forms of plaques that are widespread, taking fulllength lumen, causing marked luminal obstruction and most probably in calcific stage preventing stitching can be dealt with aggressive traction and separation from the coronary wall regaining full luminal patency (touch the plaque endarterectomy technique). Because of the increased operative risk of endarterectomy, the arteriotomy should extend in both proximal and distal directions to the plaque until a good soft landing zone of normal intima to secure safe and efficient anastmosis (open endarterectomy) with/without patch plasty $[3,13]$

Two known techniques of endarterectomy are generally applied worldwide. However, it is controversial to select the optimal method. Touch the plaque closed-traction technique is done via blind simple traction of the vessel intima through a small proximal arteriotomy incision [3]. It seems easy and simple approach taking no much time with simple easy anastmosis. However, it carries many disadvantages like the most possible event of torning-off diagonal branches and the important septal perforators (even with gentle traction) endangering myocardial revascularization. Also luminal distal end may be obstructed due to dissected wall or thrombus rendering revascularization inefficient [14]. In contrast, touch the plaque open technique described as extended arteriotomy and direct visualization of the wall intima allows total plaque removal, observing the side branches openings and the distal end of the vessel confidentially and fixing torn or divided intima during the maneuver [3]. Furthermore, anastmosis can be performed perfectly ensuring un-occluding the side branches that originate from the affected anastmotic vessel segment [12]. Because the major goal of CABG is to restore sufficient blood flow to the main coronaries and their side branches, simple distal arteriotomy seems inefficient and non-beneficial. This technique secures sufficient blood supply through direct eradication of the plaque sequence [15]. One more advantage of great importance is obtaining good anastmotic site after plaque removal because when there is severely calcified plaque, conventional anastmosis is difficult and not secured [16] Thus, complete revascularization is secured by this technique. So, we adapted this technique in dealing with grafting the severely diffused LAD that showed good results in agreement with others $[3,7,13,14,15,16]$. Our utilization of LIMA patch plasty added more benefit to the procedure. It enlarged the grafted LAD lumen. LIMA has the well-known advantage of better vasomotor function in terms of controlling the blood flow in proportion to the distal run-off supply based on its endothelial paracrine function releasing prostacycline and other relaxation factors [17]

Although some reports have been emerged demonstrating safely-performed endarterectomy during off-pump CABG [10,18,19], we believe in agreement with others that efficiently-done endarterectomy is best carried out using on-pump method $[3,20]$.

Endarterectomy technique is still avoided by many cardiac surgeons based on the controversy concerning vessel luminal patency and possible adverse complications of the procedure [21]. Some authors think that it may stimulate myo-fibrointimal proliferation and induce a coagulation cascade in the immediate postoperative period resulting in thrombosis, marked ischemia or progression to massive myocardial infarction [22] However, in the present study, we did not face such complications as what was mentioned by other reports [3,4]. We adapted tight anticoagulation control measures (anticoagulants and antiplatelets) starting 6 hours after the operation extending to 6 months postoperatively controlling INR to be 1.5 2 . Thus, this management may confirm the theory that anticoagulation regimen is efficient in preventing post-endarterectomy coagulation cascade and thrombus formation $[\mathbf{3 , 4 , 2 3}]$

In the present study adapting the "Touch the plaque open technique of LAD endarterectomy", no over-burden was added to the surgery. Yet, we found favorable operative and postoperative outcomes. No mortality occurred during the study. This comes in favor of other reports $[\mathbf{3 , 7 , 1 3}]$. However, other reports stated higher mortality rates ranging from $2.3-10.5 \%$ in comparison to conventional CABG and comparable results between closed-traction and open endarterectomy techniques $[24,25]$. This may be due to other associated comorbid conditions, risk factors, the reported usage of SVG patch plasty and the higher number of endarterectomized vessels rather than endarterectomy procedure per se. We used LIMA patch plasty in a single endarterectomized vessel (LAD). In agreement with others, the utilization of LIMA patch plasty (which improves patency of the graft) rather than venous grafts and avoiding multivessels endarterectomy may improve mortality $[3,25]$

The feared-of postoperative thrombotic complication (postoperative MI) did not happen in the study as well as other reports [3]. This may be 
attributed to the strictly followed anticoagulation management protocol and our routine utilization of LIMA patch plasty. Some reports expressed 3$5 \%$ perioperative $\mathrm{MI}$ in the LAD territory postendarterectomy [12]. Other reports mentioned 7.3\% [25]. It is worthy to note that currently there is inefficient evidence correlating open endarterectomy with MI incidence [25] .

The other postoperative expected adverse events were in the accepted range as any other conventional CABG surgery and the overall in-hospital complication rate was $28.57 \%$ comparable to other reported conventional CABG surgeries [26,27]. Of great importance to mention in this study is the significant improvement of the LVEF\% and its good impact on the functional and overall clinical status of the patients at one-year follow-up. A finding that was met by others [3,9]. Overall oneyear survival rate was $100 \%$ which comes in favor with other reports mentioned improvement of 3-, 4- and 5-year survival rates when open endarterectomy utilizes LIMA patch plasty [25]

\section{Conclusion:}

The main and principal target of CABG is to secure total and complete myocardial revascularization. To achieve this goal in the presence of severely diffusely diseased LAD (which is the most important target), more complex highly-technical maneuvers are to be attempted. Touch the plaque open technique of LAD endarterectomy combined with LIMA patch plasty provides satisfactory operative and postoperative results without adding more burden to the surgery. It secures complete revascularization of the LAD myocardial territory and improvement of the left ventricular function and resultant improvement of the clinical and haemodynamic status of the patients. Utilization of LIMA patch plasty and strict anticoagulation management postoperatively is highly recommended.

\section{Study limitations:}

This study is a retrospective one, with relatively small number of cases, done by a single surgeon. Follow-up was based upon only clinical evaluation and echocardiography assessment not entailing angiography. Duration of follow-up and survival rate estimation was for one year, thus, longer follow-up periods are mandatory to establish the results.

\section{Conflict of interest:}

None.

\section{Funding:}

Self-funded.

\section{References}

1- BARRA J.A., BEZON E., MONDINE P., RESK A., GILARD M. and BOSHAT J.: Coronary artery reconstruction for extensive coronary disease: 108 patients and two year follow-up. Ann. Thorac. Surg., 70: 1541-5, 2000.

2- SIRIVELLA S., GIELCHINSKY I. and PARSONNET $\mathrm{V}$.: Results of coronary artery endarterectomy and coronary artery bypass grafting for diffuse coronary artery disease. Ann. Thorac. Surg., 80: 1738-44, 2005.

3- MANOCHIHR TIMORIAN, MIRWAIS AMIRI and ABDULLAH ALIMI: Coronary Endarterectomy Improve Left Ventricle Ejection Fraction After Coronary Artery Bypass Grafting SURGERY. International Journal of Cardiovascular and Thoracic Surgery, 5 (2): 41-46, 2019.

4- FUKUI T., TAKANASHI S. and HOSODA Y.: Long segmental reconstruction of diffusely diseased left anterior descending coronary artery with left internal thoracic artery with or without endarterectomy. Ann. Thorac. Surg., 80: 2098-05, 2005.

5- BAILEY C., MAY A. and LEMMON W.: Survival after coronary endarterectomy in man. JAMA, 164: 461-6, 1957.

6- DJALILIAN A.R. and SHUMWAY S.J.: Adjunctive coronary endarterectomy: Improved safety in modern cardiac surgery. Ann. Thorac. Surg., 60: 1749-54, 1995.

7- KLEISLI T., CHENG W., JACOBS M.J., MIROCHA J., DEROBERTIS M.A., KASS R.M., BLANCHE C., FONTANA G.P., RAISSI S.S., MAGLIATO K.E. and TRENTO A.: In the current era, complete revascularization improves survival after coronary artery bypass surgery. J. Thorac. Cardiovasc. Surg., 129: 1283-91, 2005.

8- BLAHA J., KOPECKY P., MATIAS M., HOVORKA R. KUNSTYR J., KOTULAK T., et al.: Comparison of three protocols for tight glycemic control in cardiac surgery patients. Diabetes Care, 32 (5): pp. 757-761, 2009.

9- SHAPIRA O.M., AKOPIAN G., HUSSAIN A., et al.: Improved clinical outcomes in patients undergoing coronary artery bypass grafting with coronary endarterectomy. Ann. Thorac. Surg., 68: 2273-8, 1999.

10- FUKUI T., TAKANASHI S., HOSODA Y. and SUEHIRO S.: Early and midterm results of off-pump coronary artery bypass grafting. Ann. Thorac. Surg., 83: 115-9, 2007.

11-OGUS T.N., BASARAN M., SELIMOGLU O., YILDIRIM T., OGUS H., OZCAN H. and US M.H.: Long-term results of the left anterior descending coronary artery reconstruction with left internal thoracic artery. Ann. Thorac. Surg., 83: 496-501, 2007.

12- HEO W., MIN H.K., KANG D.K., LEE S.K., JUN H.J. and HWANG Y.H. : Long segmental reconstruction of diffusely diseased left anterior descending coronary artery using left internal thoracic artery with extensive endarterectomy. Korean J. Thorac. Cardiovasc. Surg., 48: 285-8, 2015 .

13- MYERS P.O., TABATA M., SHEKAR P.S., COUPER G.S., KHALPEY Z.I. and ARANKI S.F.: Extensive endarterectomy and reconstruction of the left anterior descending artery: Early and late outcomes. J. Thorac. Cardiovasc. Surg., 143: 133 6-40, 2012. 
14- FUKUI T., TAKANASHI S. and HOSODA Y.: Long segmental reconstruction of diffusely diseased left anterior descending coronary artery with left internal thoracic artery with or without endarterectomy. Ann. Thorac. Surg., 80: 2098-105, 2005.

15- SHAPIRA O.M., AKOPIAN G., HUSSAIN A., ADELSTEIN M., LAZAR H.L., ALDEA G.S. and SHEMIN R.J.: Improved clinical outcomes in patients undergoing coronary artery bypass grafting with coronary endarterectomy. Ann. Thorac. Surg., 68: 2273-8, 1999.

16- WANG J., GU C., YU W., GAO M. and YU U.: Shortand long-term patient outcomes from combined coronary endarterectomy and coronary artery bypass grafting: A meta-analysis of 63, 730 patients (PRISMA). Medicine (Baltimore), 94: 1781, 2015.

17- LÜSCHER T.F., DIEDERICH D. and SIEBENMANN R.: Difference between endothelium dependent relaxations in arterial and venous coronary bypass grafts. N. Engl. J. Med., 319: 462-7, 1988.

18- ERYILMAZ S., INAN M.B., EREN N.T., YAZICIOGLU L., CORAPCIOGLU T. and AKALIN H.: Coronary endarterectomy with off-pump coronary artery bypass surgery. Ann. Thorac. Surg., 75: 865-9, 2003.

19- VOHRA H.A., KANWAR R., KHAN T. and DIMITRI W.R.: Early and late outcome after off-pump coronary artery bypass graft surgery with coronary endarterectomy: A single-center 10-year experience. Ann. Thorac. Surg., 81: 1691-6, 2006.

20- NATHOE H.M., BUSKENS E., JANSEN E.W., SUYKER W.J., STELLA P.R., LAHPOR J.R., VAN BOVEN W.J., VAN DIJK D., DIEPHUIS J.C., BORST C., MOONS K.G., GROBBEE D.E. and de JAEGERE P.P.: Role of coronary collaterals in off-pump and on-pump coronary bypass surgery. Circulation, 110: 1738-42, 2004.
21- SUNDT ${ }^{3 \text { rd }}$ T.M., CAMILLO C.J., MENDELOFF E.N., BARNER H.B. and GAY Jr. W.A.: Reappraisal of coronary endarterectomy for the treatment of diffuse coronary artery disease. Ann. Thorac. Surg., 68: 1272-7, 1999.

22- FUKUI T., TABATA M., TAGURI M., MANABE S., MORITA S. and TAKANASHI S.: Extensive reconstruction of the left anterior descending coronary artery with an internal thoracic artery graft. Ann. Thorac. Surg., 91: 445-51, 2011.

23- SCHWANN T.A., ZACHARIAS A., RIORDAN C.J., DURHAM S.J., SHAH A.S. and HABIB R.H.: Survival and graft patency after coronary artery bypass grafting with coronary endarterectomy: Role of arterial versus vein conduits. Ann. Thorac. Surg., 84: 25-31, 2007.

24- TIRUVOIPATI R., LOUBANI M. and PEEK G.: Coronary endarterectomy in the current era. Curr. Opin. Cardiol., 20: 517-20, 2005

25- SOYLU E., HARLING L., ASHRAFIAN H. and ATHANASIOU T.: Does coronary endarterectomy technique affect surgical outcome when combined with coronary artery bypass grafting? Interact Cardiovasc Thorac. Surg. Nov., 19 (5): 848-55, 2014.

26- MOURSI I. and AL FAKHARANY K.: Prognosis of diabetic coronary artery bypass graft surgerypatients. Journal of the Egyptian Society of Cardio-Thoracic Surgery 25: 294-300, 2017

27- HALKOS M.E., LATTOUF O.M., PUSKAS J.D., KILGO P., COOPER W.A., MORRIS C.D., GUYTON R.A. and THOURANI V.H.: Elevated preoperative hemoglobin A1c level is associated with reduced long-term survival after coronary artery bypass surgery. Ann. Thorac. Surg., 86: 1431-1437, 2008.

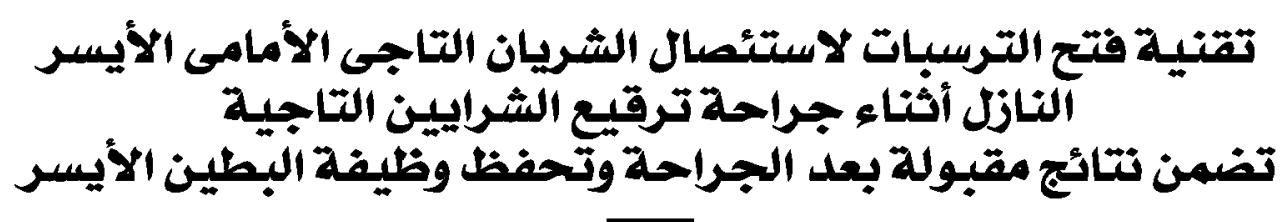

الزيادة المستمرة فى عدد حالات قصور الثرايين التاجية للقلب التى تحتاج للتدخل الجراحى والتى تعانى من تكلسات شديدة في الثريان

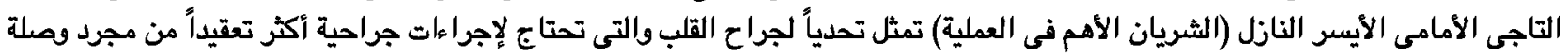

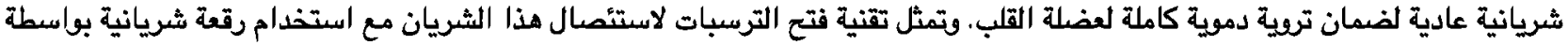

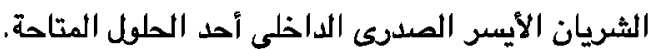

$$
\text { أجريت هذه الدراسة بهدف تقييم أثر تنفيذ هذه التقنية على نتائج ما بعد جراحة ترقيع الثرايين التاجية ووظيفة البطين الأيسر للقلب. }
$$

تم تنفيذ هذه التقنية على إحلى وعثرين مريضاً ومتابعتهم على مدار عام بعد إجراء الجراحة. وأظهرت الدراسة علم حدوث وفيات أثناء

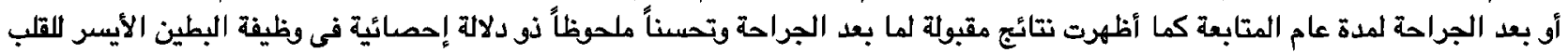
وكذلك الصالة الصحية المرضى.

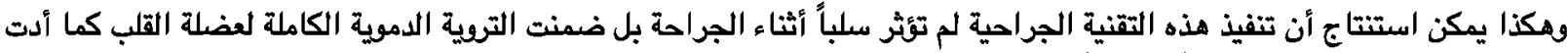

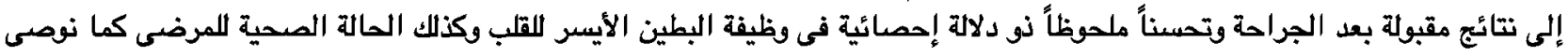
باستخدام عقارات منع التجلط الدمعى بعد بعد الجراحة. 